\title{
Helicobacter pylori virulence factor CagA promotes tumorigenesis of gastric cancer via multiple signaling pathways
}

\author{
Xin Yong, Bo Tang, Bo-Sheng Li, Rui Xie, Chang-Jiang Hu, Gang Luo, Yong Qin, Hui Dong and Shi-Ming Yang*
}

\begin{abstract}
Helicobacter pylori (H. pylori) infection is strongly associated with the development of gastric diseases but also with several extragastric diseases. The clinical outcomes caused by H. pylori infection are considered to be associated with a complex combination of host susceptibility, environmental factors and bacterial isolates. Infections involving H. pylori strains that possess the virulence factor CagA have a worse clinical outcome than those involving CagA-negative strains. It is remarkable that CagA-positive H. pylori increase the risk for gastric cancer over the risk associated with H. pylori infection alone. CagA behaves as a bacterial oncoprotein playing a key role in H. pylori-induced gastric cancer. Activation of oncogenic signaling pathways and inactivation of tumor suppressor pathways are two crucial events in the development of gastric cancer. CagA shows the ability to affect the expression or function of vital protein in oncogenic or tumor suppressor signaling pathways via several molecular mechanisms, such as direct binding or interaction, phosphorylation of vital signaling proteins and methylation of tumor suppressor genes. As a result, CagA continuously dysregulates of these signaling pathways and promotes tumorigenesis. Recent research has enriched our understanding of how CagA effects on these signaling pathways. This review summarizes the results of the most relevant studies, discusses the complex molecular mechanism involved and attempts to delineate the entire signaling pathway.
\end{abstract}

Keywords: Helicobacter pylori CagA, Wnt/B-catenin, PI3K/Akt, p53

\section{Introduction}

Helicobacter pylori (H. pylori) is the most common human pathogen worldwide, infecting an estimated $50 \%$ of the global population [1]. During H. pylori infection, sustained inflammation and abnormal epithelial proliferation may be major factors that lead to $H$. pylori-associated gastric diseases, such as gastritis, peptic ulcers, mucosaassociated lymphoid tissue lymphoma and gastric cancer. Further studies have indicated that $H$. pylori is responsible for several extragastric diseases, such as iron deficiency anemia and idiopathic thrombocytopenic purpura $[1,2]$. Interesting associations have also been noted between $\mathrm{H}$. pylori and other extragastric diseases, such as cardiovascular, neurological, hepatobiliary, colonic and pancreatic diseases [2]. However, gastric cancer is one of the most malignant types of tumor and represents a major health

\footnotetext{
* Correspondence: shimingyang@yahoo.com

Department of Gastroenterology, Xinqiao Hospital, Third Military Medical University, Chongqing 400037, P.R. China
}

problem worldwide. The association of $H$. pylori with gastric cancer has received a great deal of attention and has been thoroughly studied. The World Health Organization and the International Agency for Research declared $H$. pylori to be a Group I human carcinogen for gastric cancer in 1994, and a prospective cohort study further implied that $H$. pylori is a necessary cause of gastric cancer [3]. H. pylori also affects the prognosis of gastric cancer. Fukase et al. performed a multi-center, open-label, randomized controlled trial to clarify that eradication of $H$. pylori should be performed after endoscopic resection of early gastric cancer to prevent the development of metachronous gastric cancer [4].

The majority of the $H$. pylori-infected population remains asymptomatic, and few individuals may develop gastric cancer. As the clinical outcomes caused by $H$. pylori infection are considered to be associated with a complex combination of host susceptibility, environmental factors and bacterial isolates [5]. The $H$. pylori 
genome shows genetic diversity among distinct isolates, and H. pylori pathogenicity is different in distinct isolates. Bacterial virulence factors exert an important influence in determining the clinical outcomes, and clinically isolated $H$. pylori strains are therefore classified according to bacterial virulence factors. The strongest candidates include the cag pathogenicity island (cag PAI) and vacuolating cytotoxin A (VacA). Clinically isolated H. pylori strains are often subdivided into two types according to the cag PAI-encoded cytotoxin-associated gene A (CagA) protein. Infections involving H. pylori strains that possess a functional cag PAI confer a higher risk for gastric cancer than those involving cag-negative strains [6]. The cag PAI is a $40 \mathrm{~kb}$ DNA fragment that encodes the CagA protein and functional components of a type IV secretion system (T4SS). The CagA protein, which is injected into gastric epithelial cells through the T4SS, behaves as a bacterial oncoprotein [7]. Ohnishi N et al. generated CagA transgenic mice that showed a significant increase in the incidence of gastric cancer. These results provide first direct evidence of the role of CagA as a bacterial oncoprotein that acts in mammals [8]. Meta-analyses further indicates that individuals infected with CagA-positive strains of $\mathrm{H}$. pylori show an increased risk for gastric cancer over the risk associated with $H$. pylori infection alone $[9,10]$.

The molecular mechanism underlying CagA-positive $H$. pylori-induced gastric cancer has been widely studied. Translocation of CagA into gastric epithelial cells is the first step in the processes of CagA-induced tumorigenesis. Several different Cag proteins are involved in the translocation of CagA. One of these proteins, CagL, functions as a component of the T4SS that binds to and activates $\alpha 5 \beta 1$ integrin receptors, triggering the delivery of the bacterial effector protein CagA to the cytoplasm of host cells [11]. Additional Cag proteins (CagY, CagI, CagA) have also been shown to bind $\beta 1$ integrin and permit translocation of the bacterial effector protein CagA $[12,13]$. Another structural component, CagE, was reported to be essential for CagA translocation. Furthermore, infection with $H$. pylori can induce phosphatidylserine (PS) externalization in epithelial cells, and CagA then interacts with the externalized PS to initiate its entry into cells [14]. Collectively, these findings indicate that $\mathrm{H}$. pylori exploits host cell surface molecules such as integrins and PS to deliver CagA to the host cells. Additionally, CagA translocation requires energy-dependent host cell processes distinct from endocytic pathways. Cytomembrane cholesterol and actin polymerization are also necessary for CagA translocation [14].

Once the protein has entered these target cells, parts of CagA molecules are tyrosine-phosphorylated by Src and Abl family kinases within several repeat Glu-ProIle-Tyr-Ala (EPIYA) motifs, while other CagA molecules remain unphosphorylated [15-17]. CagA then binds to various signaling proteins and causes dysregulation of multiple signaling pathways in either a phosphorylationdependent or phosphorylation-independent manner [18]. Phosphorylated CagA causes epithelial cells elongation and scattering, a morphology was originally referred to as the "hummingbird phenotype", due to its effect on host cell signaling pathways, such as the extracellular signalregulated kinase $(\mathrm{ERK}) /$ mitogen-activated protein kinase (MAPK) pathway, by interacting with SHP2, Grb2 and Crk/Crk-L $[19,20]$. On the other hand, unphosphorylated CagA interacts with various signaling proteins, such as Met, E-cadherin, Grb2 and Par1b, and then activates corresponding signaling pathways, such as the phosphatidylinositol 3-kinase/Akt (PI3K/Akt) signaling pathway, nuclear factor- $\mathrm{kB}(\mathrm{NF}-\mathrm{\kappa} \mathrm{B})$ signaling pathway, $\mathrm{Wnt} / \beta$-catenin signaling pathway and Ras signaling pathway, among others [21-23]. These interactions and the activation of these signaling pathways contribute to the epithelial proliferation and pro-inflammatory processes as well as the disruption of cell-to-cell junctions, or loss of cell polarity.

This review focuses on recent findings regarding CagA, related to various kinds of vital signaling proteins and several classic signaling pathways. In combination with previous studies on corresponding proteins or signaling pathways, we hope to discuss the possible molecular mechanism underlying the CagA-induced abnormal expression of vital signaling proteins and the dysregulation of signaling pathways, and to further recognize the relationship of CagA and the clinical outcomes of $H$. pylori infection, especially gastric cancer, which is the most severe outcome.

\section{CagA mediates dysregulation of the Wnt/ $\beta$-catenin signaling pathway}

The Wnt/ $\beta$-catenin signaling pathway is a key pathway regulating embryonic development and adult tissue homeostasis. Aberrant $\mathrm{Wnt} / \beta$-catenin signaling plays an essential role in disease pathogenesis, especially in tumorigenesis and progression $[24,25]$. The $\mathrm{Wnt} / \beta$-catenin signaling pathway is highly conserved among species, and the core of this pathway is the versatile protein $\beta$-catenin, encoded by CTNNB1. The canonical Wnt/ $\beta$-catenin signaling pathway is activated by a secreted extracellular Wnt ligand that binds to frizzled (Fzd) receptors and their co-receptors the low-density lipoprotein receptor related protein (LRP) families. The activated Fzd receptor switches on the intracellular signaling cascade. Then the phosphorylation of LRP activates the disheveled protein (Dvl), which in turn inactivates a complex of proteins collectively termed the "destruction complex", including the core proteins glycogen synthase kinase-3 $\beta$ (GSK-3 $\beta$ ), Axin, adenomatosis polyposis coli (APC) and casein kinase-1 
(CK-1). In the absence of Wnt ligands or the presence of abundant competitive ligands, such as Wnt inhibitory factor-1(WIF-1), secreted Frizzled related proteins (sFRPs), or Dickkopf family proteins (DKKs), the destruction complex phosphorylates the $\mathrm{N}$-terminus of cytosolic $\beta$-catenin, and targets it for proteasomal degradation, thereby maintaining $\beta$-catenin at low baseline cytosolic levels. However, in the presence of Wnt ligands, cytosolic $\beta$-catenin can not be phosphorylated due to inactivation of the destruction complex. As a result, $\beta$ catenin is stabilized and accumulates in the cytoplasm and subsequently translocates to the nucleus. In the nucleus, $\beta$-catenin interacts with the T cell factor/lymphoid enhancer factor (TCF/LEF) family of transcription factors to induce target gene transcription $[26,27]$.

Dysregulation of the Wnt/ $\beta$-catenin signaling pathway is widely implicated in gastrointestinal cancers, including colorectal cancer and gastric cancer [27, 28]. Mutation of pathways components (eg. Axin and $\beta$-catenin), inhibition of antagonists (eg. sFRPs) or crosstalk with other signaling pathways leads to continuous dysregulation of the Wnt/B-catenin signaling pathway. Infection by Pathogenic microorganisms, such as H. pylori, Hepatitis virus, is another important factor influencing the Wnt/ $\beta$-catenin signaling pathway [29-33]. Franco et al. reported that CagA-positive H. pylori altered $\beta$-catenin localization and increased $\beta$-catenin nuclear accumulation in gastric epithelial cells AGS. Along with $\beta$-catenin nuclear translocation, the Wnt/ $\beta$-catenin signaling pathway is activated. These authors also observed this phenomenon in gerbil gastric mucosae and human gastric mucosae colonized by CagA-positive H. pylori [29]. Another study further confirmed that the nuclear translocation of $\beta$-catenin and subsequent activation of the $W n t / \beta$-catenin signaling by CagA required the EPIYA repeat region and was independent of CagA tyrosine phosphorylation [30]. Neal et al. generated transgenic zebrafish expressing CagA and found the $\mathrm{Wnt} / \beta$-catenin target genes significant upregulation in the transgenic zebrafish. The functional consequences of the CagAactivated $\mathrm{Wnt} / \beta$-catenin signaling pathway included increased intestinal proliferation. These results provided in vivo evidence of CagA-induced Wnt/ $\beta$-catenin signaling pathway activation [31].

Under physiological conditions, $\beta$-catenin interacts with the cytoplasmic tail of E-cadherin to form adherens junctions between epithelial cells. However, upon infection with CagA-positive H. pylori strains, CagA will become competitive in combination with E-cadherin and disrupt complex formation between E-cadherin and $\beta$ catenin, causing cytoplasmic and nuclear accumulation of $\beta$-catenin. In addition, the interaction between CagA and E-cadherin is independent of CagA tyrosine phosphorylation, but the specific binding sites involved are not clear (Fig. 1a) [22]. Therefore, they may be directly bound or indirectly bound via another component of the adherens junction complex. Although the details of the interaction between CagA and E-cadherin remain to be elucidated, this research provided the molecular mechanism of CagA deregulation of $\beta$-catenin and subsequent activation of the canonical Wnt/ $\beta$-catenin signaling pathway. AGS gastric epithelial cells are commonly used in the study of $H$. pylori because these cells are highly susceptive to $H$. pylori infection. Interestingly, AGS do not form E-cadherin/ $\beta$-catenin complexes due to a lack of E-cadherin expression, and CagA is therefore not able to release of $\beta$-catenin from the $\mathrm{E}$-cadherin $/ \beta$-catenin compelx. Nevertheless, CagA still increases the cytoplasmic and nuclear accumulation of $\beta$-catenin in AGS cells and activates the $\mathrm{Wnt} / \beta$-catenin signaling pathway $[21,29]$. Thus, there may be other mechanisms through which CagA regulates $\beta$-catenin and the $\mathrm{Wnt} / \beta$-catenin signaling pathway.

Wnt ligands/receptors or the components of the destruction complex may be involved in the CagA-positive $H$. pylori-induced activation of the Wnt $/ \beta$-catenin signaling pathway. It has been reported $H$. pylori induces rapid activation of the $\mathrm{Wnt} / \beta$-catenin signaling pathway co-receptor LRP6, which is dependent on proteins of Dvl family (Fig. 1b) [34]. Although this process was found to be independent of CagA, $H$. pylori lacking a functional T4SS failed to induce LRP6 phosphorylation and activation. It is still unclear how $H$. pylori activates LRP6 and whether there is a direct relationship between H. pylori and Dvl. Sokolova et al. reported that H. pylori suppressed GSK-3 $\beta$ activity to promote $\beta$-catenin activity in a CagA-independent manner [35]. Subsequently, Nakayama et al. reported that $H$. pylori VacA induced the phosphorylation and inactivation of GSK-3 $\beta$ through the PI3K/Akt signaling pathway, and subsequent nuclear translocation of $\beta$-catenin regulated transcriptional activity [36]. Tabassam et al. came to a similar conclusion, that $H$. pylori induced GSK-3 $\beta$ inactivation via the PI3K/ Akt signaling pathway, but their results showed that CagA was responsible for GSK-3 $\beta$ inactivation and downstream $\beta$-catenin activation (Fig. 1c) [37]. These opposing results may be due to the differences in the cell lines and $H$. pylori strains used in the research. Sokolova et al. mainly employed MDCK cells and an $H$. pylori strain P1 expressing CagA. They confirmed that CagA could be translocated and phosphorylated at tyrosine residues in both AGS and MDCK cells, but they did not verify the following results in AGS cells. Similarly, Nakayama et al. only used the AZ-521 cell line in their research, and this cell line has been used relatively less frequently in research on $H$. pylori. Recently, Korean researchers explained H. pylori CagA-induced GSK-3 $\beta$ inactivation from another perspective. They indicated that 


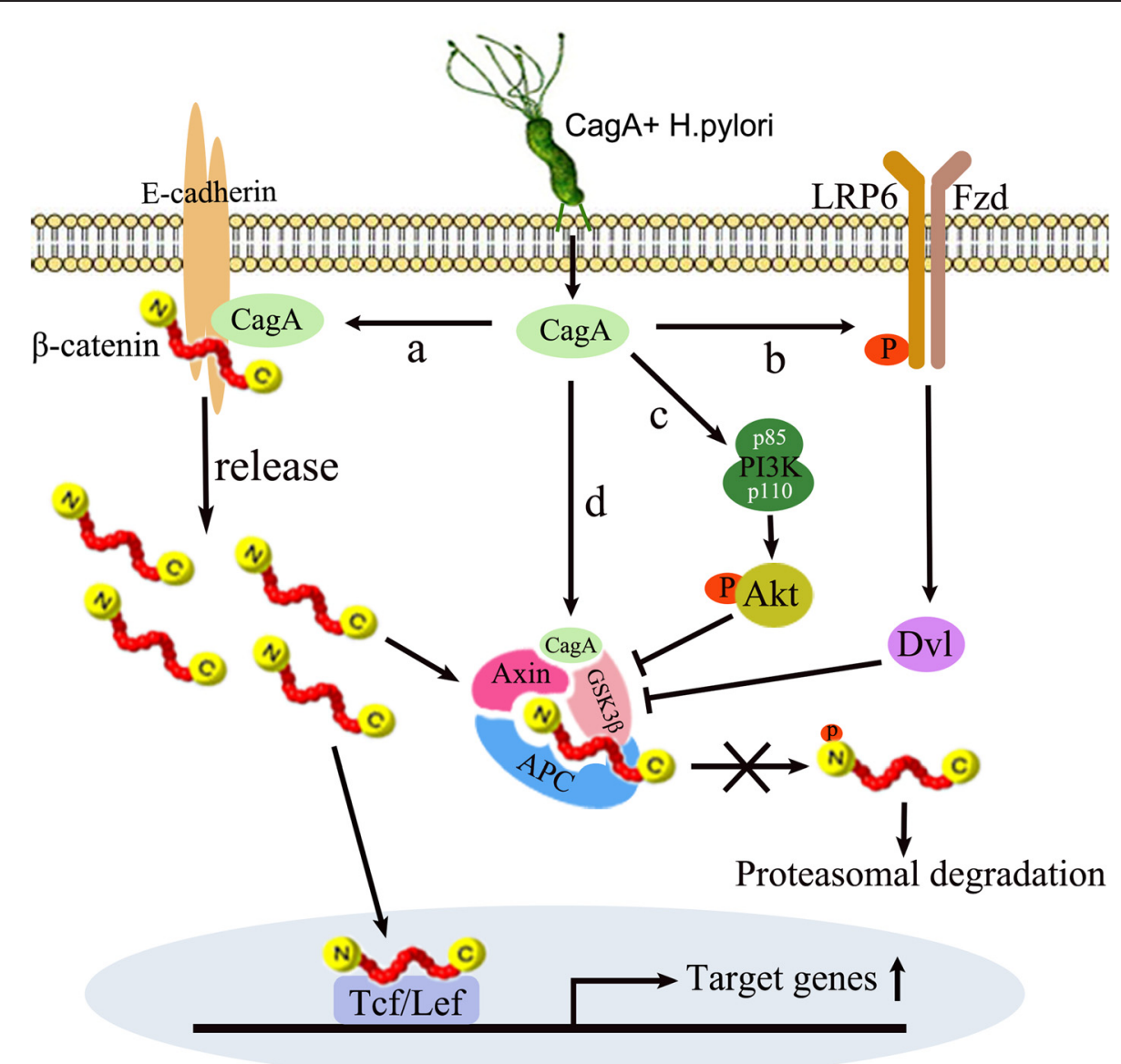

Fig. 1 CagA mediates dysregulation of the Wnt/B-catenin signaling pathway. a. CagA competitively combines with E-cadherin and disrupts the E-cadherin/ $\beta$-catenin complex formation, causing cytoplasmic and nuclear accumulation of $\beta$-catenin. b. H. pylori induces rapid phosphorylation

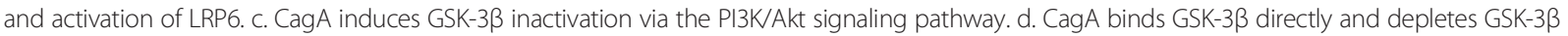
activity, inhibiting the phosphorylation and proteasomal degradation of cytosolic $\beta$-catenin

CagA could directly bind GSK-3 $\beta$ and deplete GSK-3 $\beta$ activity. Furthermore, they found that the C-terminal region of CagA harbored an EPIYA motif and a multimerization domain that played an important role in the binding and depletion of GSK-3 $\beta$ (Fig. 1d) [38]. This result is consistent with previous findings showing that the EPIYA repeat region is responsible for $\beta$-catenin activation [30]. Taken together, these results show that CagA mediates dysregulation of the $\mathrm{Wnt} / \beta$-catenin signaling pathway via effecting the release and degradation of $\beta$ catenin.

\section{CagA activates PI3K/Akt and the downstream signaling pathways}

PI3K, which is involved in tumorigenesis, is a heterodimer consisting of a p85 regulatory subunit and a p110 catalytic subunit. The main function of PI3K is to phosphorylate phosphatidylinositol in the cytomembrane and convert it into phosphatidylinositol 3, 4, 5-triphosphate (PIP3). PIP3 interacts with the pleckstrin homology (PH) domain of a ser/thr kinase Akt and allows Akt phosphorylation at Ser473 or Thr308. This phosphorylation activates Akt, which in turn, activates or inactivates downstream tyrosine kinase- and G-protein-coupled receptors in turn. GSK-3 $\beta$, NF- $\mathrm{kB}$ and mammalian target of rapamycin (mTOR) are key representative of PI3K/ Akt downstream target proteins [37, 39-44], and the MEK/ERK signaling pathway is a representative of PI3K/ Akt downstream signaling pathway [45].

The PI3K/Akt signaling pathway is hyperactive in some cancers, including gastric cancer [46, 47]. H. pylori infection is a major factor in the activation of PI3K/Akt and downstream signaling pathways $[21,37,44]$. The activation of PI3K/Akt signaling pathways is a response to growth factors (eg. epidermal growth factor, hepatocyte growth factor). As the specific receptors of epidermal growth factor and hepatocyte growth factor, the epidermal growth factor receptor (EGFR) and c-met, respectively, mediate the activation of the PI3K/Akt signaling pathway. H. pylori infection induces the phosphorylation 
of EGFR Tyr 992 and the transactivation of EGFR, which is dependent on CagA and another virulence factor, OipA. As a result, the PI3K p85 subunit is activated, and two specific phosphorylation sites (Thr 308 and Ser 473 of Akt) are phosphorylated. Importantly, the CagA mutation reduces the activation of Akt Thr 308, whereas the oipA mutation reduces the levels of Akt Ser 473 in response to $H$. pylori infection. Double CagA/OipA mutation results in complete inhibition of the phosphorylation of Akt Ser 473, confirming that CagA mainly affects the phosphorylation of Akt Ser 473 [37]. Interestingly, EGFR is activated by $H$. pylori during early infection, but $H$. pylori CagA inactivates EGFR during prolonged infection via reducing the phosphorylation of EGFR tyrosine residues [48]. This research revealed that CagA-positive H. pylori regulates EGFR activation and inactivation to support persistent infection. But it is regrettable that the EGFR/PI3K/Akt signaling pathway is not mentioned in this paper. Thus, the role of EGFR in $H$. pylori-induced signaling pathways is not completely clear and needs to be investigated more thoroughly in the future. However, it has been confirmed that c-met is activated in H. pylori-infected conditions, and CagA is able to interact with activated c-met $[21,49]$ Moreover, the C-terminal region of CagA, which is designated CRPIA (conserved repeat responsible for phosphorylation-independent activity), is involved in the interaction with c-met and the activation of the downstream PI3K/Akt signaling pathway. As a results of CagA-induced PI3K/Akt signaling pathway activation, GSK3 $\beta$, which is a downstream target of PI3K/Akt, is inactivated, and $\beta$-catenin transcription is subsequently activated [21,37]. In other words, there is a crosstalk between the CagA-induced Wnt/ $\mathrm{W}$-catenin signaling pathway and the PI3K/Akt signaling pathway.

Recently, Zhang et al. found CagA EPIYA repeat region was also involved in the activation of PI3K/Akt signaling pathway [50]. The EPIYA repeat region of CagA is classified into 4 tyrosine phosphorylation motifs (TPMs), A-, B-, C- or D-TPMs. Western CagA has A-, B-, and C-TPMs, while East Asian CagA possesses A-, B-, and D-TPMs [51, 52]. Zhang et al. demonstrated CagA activated PI3K/Akt signaling pathway by interaction with PI3K via a functional B-TPM. Through database searching and silico analysis, they revealed a strong non-random distribution of the B-TPM polymorphisms (A/T polymorphism, including EPIYA and EPIYT) in Western H. pylori isolates. And Matsunari et al. previously also reported that B-TPM polymorphisms (EPIYT, EPIYA, ESIYA and so on) and that EPIYT of B-TPM was more predominant in Western $H$. pylori isolates and EPIYA of B-TPM was more predominant in East Asian H. pylori isolates [53]. Interestingly, during co-culture with AGS cells, an H. pylori strain with EPIYT B-TPM had higher affinity to PI3K and significantly enhanced induction of PI3K/Akt signaling pathway, compared to the isogenic strain with EPIYA B-TPM [50]. These results suggest that the $\mathrm{A} / \mathrm{T}$ polymorphisms in B-TMP could regulate PI3K/Akt signaling pathway activity through influencing the interaction between CagA and PI3K. In addition, $H$. pylori strain with EPIYT B-TPM induced less hummingbird cells and IL-8 levels than the isogenic strain with EPIYA B-TPM [50]. In this regard, the differential EPIYT and EPIYA functions might be part of the reason that the incidence of gastric carcinoma is much higher in East Asian countries than in Western countries. However, it is regrettable that there is no direct result confirms the relationship between PI3K/Akt signaling and hummingbird phenotype and IL-8 levels. Indeed, it is difficult to use a simple linear relationship to clarify the regulation of PI3K/Akt signaling on hummingbird phenotype and IL-8 levels, because (i) PI3K/Akt downstream target proteins or signaling pathways are pleiotropic and have complex crosstalk with other signaling pathways, (ii) $H$. pylori could induce AGS hummingbird phenotype and IL-8 production through multiple CagA-mediated mechanisms.

NF- $\mathrm{kB}$, which is a downstream target of PI3K/Akt, is a crucial regulator of many cellular processes, including inflammation, immune responses and tumorigenesis. NF- $\mathrm{kB}$ is a p65/p50 heterodimer that forms a complex with cytoplasmic inhibitors (eg. IкB) in resting condition. PI3K/Akt can activate IKB kinase (IKK), which phosphorylates I $\mathrm{I} B$ and subsequently releases NF- $\mathrm{kB}$ from the complex. Then NF- $\mathrm{kB}$ translocates to the nucleus, and phosphorylation of the p65 subunit plays a key role in the NF- $\mathrm{kB}$-mediated transcriptional response. It has been accepted that $H$. pylori cag PAI is required for NF-kB activation $[54,55]$, but the role of CagA in the regulation of $\mathrm{NF}-\mathrm{kB}$ activity is still a subject of intense discussion. Early studies found that $H$. pylori induced NF- $\mathrm{kB}$ activation in time-, multiplicity of infection-, and cag PAI-dependent manners [54]. Recently, Sokolova further confirmed that H. pylori cag PAI encoding T4SS was required for activation of NF- $\mathrm{kB}$ and release of downstream IL-8, but CagA had only a partial or minor role in NF- $\mathrm{kB}$ activation and IL-8 release at early infection [55]. In contrast, Brandt et al. found that CagA could activate NF- $\mathrm{kB}$ and induce downstream IL-8 release in a time-dependent manner [56]. In this study, CagA activates NF-kB and induces IL-8 induction via the MEK/ERK signaling pathway. Subsequently, Kim et al. constructed CagA and its fragments eukaryotic expression vectors, and further confirmed that NF- $\kappa B$ activation and IL-8 release induced by CagA occurred via the MEK/ERK signaling pathway activation [57]. Recently, Kang et al. compared different CagApositive and -negative $H$. pylori strains for their ability to activation of NF- $\mathrm{kB}$ in different gastric cancer cells. They confirmed that CagA was required for $H$. pylori-induced 
activation of NF-kB and that CagA selectively induced Phospholipase D1 expression via NF-kB [58]. The different $H$. pylori strains used by different laboratories may be responsible for different components of $H$. pylori that drive NF- $\mathrm{kB}$ signaling pathway. However, the time point of $H$. pylori infection may be the main factor determing which component drive NF- $\mathrm{kB}$ signaling pathway. Most of the previous studies compared different CagA-positive and -negative H. pylori strains for their ability to activation of NF- $\mathrm{kB}$ at early time points of infection (less than $3 \mathrm{~h}$ ). They found $H$. pylori induced NF- $\kappa \mathrm{B}$ activation and IL-8 release in a CagA-independent manner $[54,55]$. Interestingly, during persistent infection (more than $12 \mathrm{~h}$ ), NF-kB activation and IL-8 release further increased in a CagAdependent manner $[56,58]$. It is may be meaningful to explore how T4SS initiate NF- $\mathrm{kB}$ signaling pathway and how CagA is involved in NF- $\mathrm{KB}$ activation during persistent infection. Transforming growth factor- $\beta$-activated kinase 1 (TAK1) is a key regulator of signal transduction cascades that lead to the activation of IKK and NF-кB. CagA physically interacts with TAK1 and enhances the activity of TAK1, which is required for NF- $\mathrm{kB}$ activation by CagA [59]. However, a later study has shown that this is a misinterpretation because the antibody against TAK1 immunoprecipitated to some extent the CagA protein by unknown reasons, while in a reverse immunoprecipitation using a CagA antibody they also could not recognise co-immunoprecipitated TAK1 [60]. Although they indicate TAK1 is not a target of the $H$. pylori CagA, TAK1 is required for $H$. pylori-induced NF- $\mathrm{kB}$ activation in a T4SS-dependent and CagA-independent manner during early infection. Actually, H. pylori-induced interaction between TAK1 and IKK complex may be involved in NF- $\mathrm{kB}$ initial activation in a T4SSdependent manner during early infection, while CagA may be play a role in extend the activation of NF- $\mathrm{kB}$ during persistent infection because CagA takes more time to be delivered into the host cells and regulates its target proteins or signaling pathways. As mentioned in the previous studies, CagA need more time to enhance NF- $\mathrm{kB}$ activity and increase IL-8 release during persistent infection [56, 58]. Therefore, further studies are necessary to elucidate the mechanisms of $H$. pyloriinduced interaction between TAK1 and IKK complex during early infection and the exact function of CagA in the regulation of NF- $\mathrm{KB}$ activity during persistent infection.

H. pylori CagA has the ability to activate of the PI3K/ Akt signaling pathway, but the regulation of the PI3K/ Akt downstream signaling pathways by $H$. pylori is still not completely clear. As an upstream regulator of NF$\mathrm{kB}, \mathrm{PI} 3 \mathrm{~K} /$ Akt is not mentioned in $\mathrm{H}$. pylori-mediated activation of NF-kB. Similarly, it has been reported that $H$. pylori activates the PI3K/Akt/mTOR signaling pathway in a CagA-independent manner [44]. As we mentioned above, CagA and OipA can phosphorylate Akt and activate the PI3K/Akt signaling pathway, but only OipA is required for $H$. pylori-induced inactivation of the Forkhead transcription factors of class $\mathrm{O}$ (FoxO) family members FoxO1 and FoxO3a, which are the downstream of PI3K/ Akt [61]. These findings indicate that $H$. pylori can activate PI3K/Akt and downstream signaling pathways via different molecules and mechanisms, maintaining the dysregulation of these signaling pathways and forming a complex network.

\section{The role of CagA in other oncogenic signaling pathways}

Similar to the $\mathrm{Wnt} / \beta$-catenin signaling pathway, the Hedgehog (Hh) signaling pathway plays a critical role in embryonic development, adult tissue homeostasis and tumorigenesis [62]. H. pylori infection induces upregulation of sonic hedgehog (Shh), which activates the $\mathrm{Hh}$ signaling pathway in gastric cancer cells. Moreover, Shh overexpression is CagA-dependent and is mediated through the NF- $\kappa B$ signaling pathway [63]. Shh is mainly expressed in parietal cells, influencing fundic gland differentiation and function. Recently, Schumacher et al. used a mouse model that expresses Shh fused to green fluorescent protein, in place of wildtype Shh to visualize Shh ligand expression in response to $H$. pylori infection in vivo. They found that $H$. pylori induced Shh overexpression in parietal cells that was consistent with the expression pattern observed in the native tissue. Furthermore, they confirmed that NF-kB signaling mediated $H$. pylori-induced Shh overexpression and that CagA is involved in this process [64]. In addition, in the early stages of $\mathrm{H}$ pylori infection, $H$. pylori-induced Shh overexpression from parietal cells acts as a macrophage chemoattractant to drive the innate immune response during the initiation of gastritis [65].

Since it was first discovered, the c-Jun NH2-terminal kinase (JNK) signaling pathway has been demonstrated to exhibit both tumor suppressor and pro-tumorigenic functions in different cell types and organs $[66,67]$. Infection with $H$. pylori has been shown to activate the JNK signaling pathway, and CagA is an important mediator of the activation of this signaling pathway during infection $[68,69]$. Wandler et al. used transgenic Drosophila to express CagA, and they found that CagA triggered JNK signaling pathway activation, which caused apoptosis in epithelial cells. Interestingly, when these authors employed a Ras oncogene-overexpression Drosophila metastasis model, they found that coexpression of CagA could enhance the growth and invasive potential of tumor cells through activation of the JNK signaling pathway [69]. This finding indicates that, in addition to the presence of virulence factors (eg. CagA), host genetics must also play an important role in determining the outcome of H. pylori infection. Indeed, $H$. pylori infection can persist for many 
years before the occurrence of gastric cancer. Therefore, JNK-mediated apoptosis may be an effective mechanism for limiting pathogenic effects and protecting the gastric epithelium in early infection. Under persistent $H$. pylori infection and the influence of other factors, accumulation of genetic mutations is observed. Following the acquisition of an oncogenic mutation, CagA-mediated JNK signaling pathway activation promotes tumor progression. It will be particularly valuable to further confirm the role of CagAmediated JNK signaling pathway activation in clinical tissue samples, but there has been no report of such studies to date.

Dysregulation of the Janus kinase (JAK)/signal transducers and activators of transcription 3 (STAT3) signaling pathway is observed in many cancers including gastric cancers, and it correlates with both tumor progression and a poor prognosis. Jackson and colleagues found that STAT3 activation was more pronounced in CagA-positive $H$. pylori-infected gastric tissue [70]. In this study, as the majority of bacterial pathogens mediate STAT3 activation via autocrine IL-6, it was found that IL-6 expression was increased after $H$. pylori infection, and both IL-6 and IL-11 were strongly up-regulated in gastric cancer tissue. In epithelial cells infected with $H$. pylori, STAT3 tyrosine phosphorylation, nuclear translocation and transcriptional activity are dependent on unphosphorylated CagA. Although $H$. pylori CagAmediated STAT3 activation requires IL- 6 and the gp130 receptor, autocrine activation of STAT3 by IL- 6 and IL11 is not involved in H. pylori CagA-mediated STAT3 activation [71]. Further studies may be required to elucidate the exact mechanism underlying the interaction between CagA and these relevant receptors. Moreover, H. pylori-mediated STAT3 activation shows the ability to manipulate host immunity and facilitate immune evasion [72, 73]. Recent evidence indicates that CagA increases the expression of Gram-positive specific bactericidal lectin, regenerating islet-derived (REG) $3 \gamma$, in gastric epithelial cells via activation of the STAT3 signaling pathway [72]. While the functional basis of this response is not entirely clear, these findings indicate that CagA-medicated REG3y overexpression may abolish the fitness of cohabiting Gram-positive bacteria and reduce the competition for resources between $H$. pylori and Gram-positive bacteria in the gastric mucosal niche. Finally, H. pylori may rebuild the gastric microbiome and manipulate host immunity to favor its own survival. The ability to evade the host immune response is another crucial factor in the survival of $H$. pylori in the host gastric mucosae. As DCs are key modulators of the host adaptive immune response, they are ideal targets for the pathogen's immunitymanipulating efforts. Several studies indicate that $H$. pylori infection promotes the development of tolerogenic dendritic cells (DCs) in a coculture system and in murine models [74, 75]. Recently, Rizzuti and colleagues found that $H$. pylori activated the STAT3 signaling pathway in bone marrow-derived DCs (BMDCs). Then BMDCs secrete IL-10, which activates STAT3 in DCs, thereby blunting DC maturation, inducing the tolerogenic DCs [73]. This study describes another novel mechanism of $H$. pylori facilitation of immune evasion to maintain its persistence.

The regulation of signaling pathways may be influenced by the CagA tyrosine phosphorylation status. It has been reported that unphosphorylated CagA showed preferentially activates of JAK/STAT3, whereas phosphorylated CagA enhances SHP2 binding activity and ERK/MAPK signaling pathway activation [76]. These findings indicate that the CagA tyrosine phosphorylation status affects the signal switch, providing a novel mechanism explaining $H$. pylori-mediated signaling pathways. Unphosphorylated and phosphorylated CagA often exist at the same time therefore, STAT3 and ERK/MAPK signaling activation must be abnormal during $H$. pylori infection. In support of this hypothesis, a research group observed significantly increased STAT3 and ERK/MAPK signaling activation in $H$. pylori-infected gastric tissue, which was further enhanced in the presence of CagApositive H. pylori strains [70]. Recent evidence indicates that IL-22 promotes gastric cancer development via activation of the STAT3 and ERK signaling pathways [77]. In this study, while gastric cancer cells were co-cultured with IL22-expressing cancer-associated fibroblasts (CAFs) from human gastric cancer tissues, the invasive ability of the gastric cancer cells was significantly enhanced through activation of the STAT3 and ERK signaling pathways. In fact, $H$. pylori infection also stimulates peripheral mononuclear cells and CD4-positive T cells to secrete IL-22, and IL-22 subsequently induces the expression of antimicrobial proteins (eg. RegIII $\alpha$ and lipocalin-2) in gastric epithelial cells [78]. In this regard, IL-22 may play a protective role in gastric mucosae infected by $H$. pylori, but more studies suggest that IL-22 may lead to pathological inflammation and thereby promote tumorigenesis and progression via STAT3 activation [77-80]. Th1 and Th17 are major T cell subsets that produce IL-22, and $H$. pylori is ability to induce Th1 and Th17 responses [81, 82]. Therefore, it is necessary to confirm that (i) the role of $H$. pylori-mediated upregulation of IL-22 in gastric cancer cells, (ii) the activation of STAT3 dependent on $H$. pylori-mediated IL-22 and/or $H$. pylori CagA, (iii) the role of CagA in H. pylori-mediated upregulation of IL-22.

In addition, $\mathrm{H}$. pylori-mediated signaling (including p21-activated kinase1 and ERK1/2) to actin-binding protein cortactin could regulate cell scattering and elongation in a T4SS dependent manner [83, 84]. Injected CagA further involves in the interaction of cortactin with downstream focal adhesion kinase (FAK), and this interaction increases FAK activity, which is important 
for cell scattering and elongation phenotype [83]. Cortactin plays a central role in host signaling and involves in a variety of cellular processes, including tumorigenesis, invasion and metastasis. Thus, further studies may be required to elucidate the role of $H$. pylori-hijacked cortactin in tumorigenesis in vivo. Furthermore, CagApositive $H$. pylori-induced activation of the Src/MEK/ ERK signaling pathway is involved in the upregulation of $\alpha$-enolase and ornithine decarboxylase, implying the progression of gastric diseases $[85,86]$. What's more, $H$. pylori is involved in protein kinase $\mathrm{C}$ (PKC) signaling pathway activation through PI3K, phospholipase $\mathrm{C} \gamma$ and $\mathrm{Ca}^{2+}$. As a result, PKC contributes to c-Fos upregulation and activator protein- 1 activation, leading to overexpression of matrix metalloproteinase-1 [87]. Due to the large number of the related studies, it is difficult to list all of $H$. pylori-mediated oncogenic signaling pathways. In other words, there are several known mechanisms underlying $H$. pylori-mediated gastric cancers.

\section{The role of CagA in tumor suppressor pathways}

Tumorigenesis is considered to occur as a multifactorial events. The activation of oncogenes and the inactivation of tumor suppressor genes are two key events in most cancers. Aberrant activation of oncogenes can be counteracted by tumor suppressor genes. It is more significant to enrich and explain the tumorigenic mechanism of $H$. pylori. In addition to activating several oncogenic signaling pathways, $H$. pylori also plays a key role in the inactivation of tumor suppressor pathways. p53 is a key tumor suppressor, and inactivation of p53 is a critical step in tumorigenesis and progression. Previous reports showed that $H$. pylori infection increased p53 levels in the gastric mucosae [88-90]. Subsequently, Wei et al. observed that p53 levels were dynamically altered in $H$. pylori-infected mongolian gerbil gastric tissues and cell lines. Consistent with previous reports, these authors found that p53 was increased following $H$. pylori infection for 4-6 h in mongolian gerbils, however, p53 decreased rapidly following the initial increase. Interestingly, p53 was shown to be increased again under continuous $H$. pylori infection for 12 weeks [91]. In this study, the authors confirmed that CagA-positive H. pylori phosphorylated Human Double Minute 2 (HDM2, a main E3 ubiquitin ligase), which induced p53 degradation. In addition, $H$. pylori-induced phosphorylation and activation of HDM2 could be mediated by Akt or ERK activation (Fig. 2a) [91, 92]. Cellular stresses, such as $H$. pylori-induced activation of oncogenic signaling pathways, may be responsible for the initial increase of p53. The second increase of p53 may be driven by DNA damage known to be associated with inflammatory processes. In another report, Wei et al. indicated that $H$. pylori could induce upregulation of truncated p53 isoforms that inhibit p53 function and increase the transcriptional activity of NF-kB in gastric epithelial cells (Fig. 2b) [93].

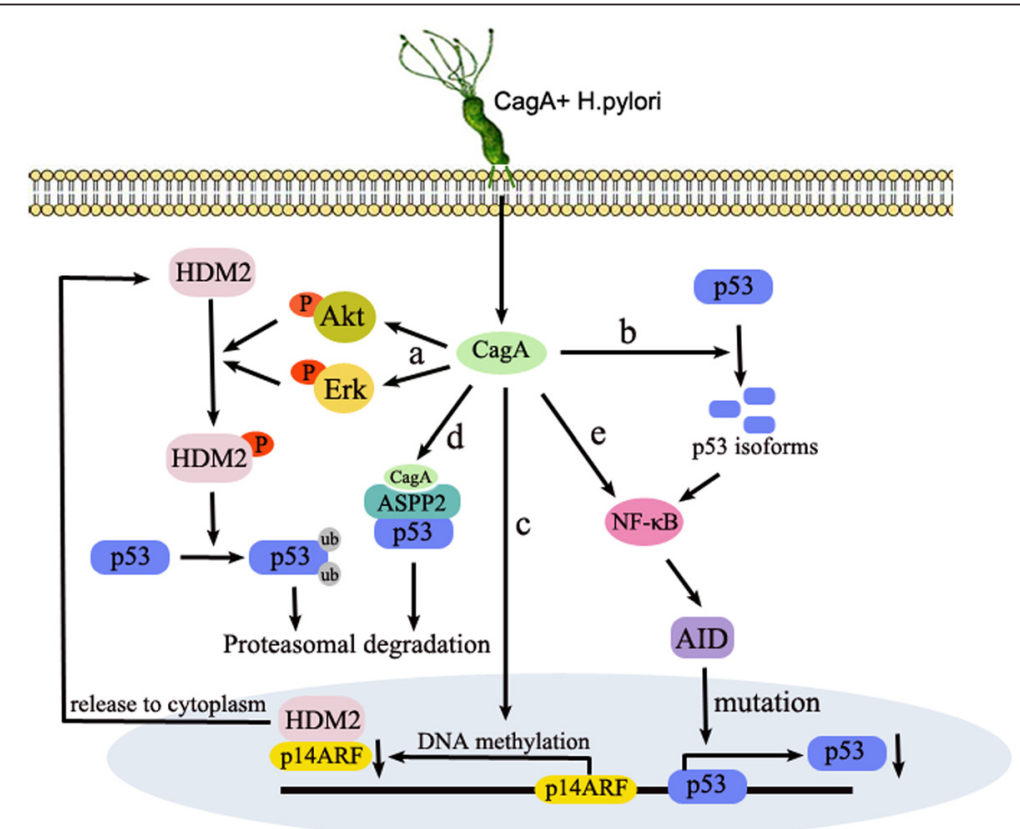

Fig. 2 The role of CagA in p53 regulation. a. CagA phosphorylation and activation of HDM2 is mediated by Akt or ERK activation. b. CagA plays a crucial role in p53 shifting to inhibitory p53 isoforms. c. CagA-induced hypermethylation of the p14ARF promoter results in a decrease in p14ARF protein levels that is not sufficient to sequester HDM2 in the nucleus. $d$. CagA interacts with ASPP2 to recruit and bind p53, which is then degraded by the proteasome. e. CagA induces aberrant expression of AID via NF-KB and thereby elicits a high mutation frequency in p53 
Taken together, these findings indicate that DNA damage-mediate upregulation of p53 may be shifted to inhibitory p53 isoforms by CagA-positive H. pylori. Inhibition of p53 may allow $H$. pylori to alter the cellular homeostasis, without apoptosis or triggering cell cycle arrest.

The p14ARF is a tumor suppressor that inhibits the proteasomal degradation of p53 by sequestering HDM2 and inhibiting its E3 ligase activity [94]. H. pylori CagAinduced hypermethylation of the p14ARF promoter results in a decrease of p14ARF protein levels that is not sufficient to inhibit HDM2 and ARF-BP1 (another E3 ubiquitin ligase) activity, and then HDM2 and ARF-BP1 then facilitates the degradation of p53 (Fig. 2c) [95]. This study provides a novel mechanism in which the CagAmediated degradation of p53 is controlled by two E3 ubiquitin ligases that are activated due to p14ARF promoter hypermethylation and downregulation of p14ARF protein levels. Apoptosis-stimulating protein of p53 (ASPP2) is best known for its role as a p53-binding protein and has also shown to act as a tumor suppressor. Following H. pylori infection, CagA shows the ability to interact with ASPP2 to form a complex. After this interaction, ASPP2 recruits and binds p53, which is then degraded by the proteasome. Although the formation of a ternary complex between CagA, ASPP2, and p53 has not been detected, it has been confirmed that the degradation of p53 is a consequence of the recruitment and misregulation of ASPP2 by CagA. As a result, CagA-mediated degradation of p53 leads to resistance to apoptosis (Fig. 2d) [96]. Recently, CagA- and ASPP2-interacting domains have been identified. The obtained co-crystal structure revealed that N-terminal subdomain of CagA forms a highly specialized three-helix bundle and that ASPP2 forms an extended helix in this groove of CagA. Consistent with previous reports, this study provides evidence that the direct interaction of CagA and ASPP2 also has an antiapoptotic effect during $H$. pylori infection [97].

P53 is inactivated by mutations in $40 \%-50 \%$ of gastric cancers. Individuals infected with CagA-positive H. pylori show a higher likelihood of harboring p53 mutations $[98,99]$. Activation-induced cytidine deaminase (AID) is a DNA and RNA mutator enzyme. In vitro studies have revealed that CagA-positive $H$. pylori induces aberrant expression of AID in gastric epithelial cells via NF- $\mathrm{kB}$ activation and thereby elicits a high mutation frequency in p53 (Fig. 2e) [100]. In addition, AID expression is elevated in $H$. pylori-positive human gastric mucosae and is reduced following H. pylori eradication [101]. A recent study in which whole-exome sequencing was performed indicated that p53 mutations accumulate in patients with $H$. pylori infection. In this study,

Table 1 CagA-positive H.pylori mediates dysregulation of multiple signaling pathways

\begin{tabular}{|c|c|c|c|}
\hline $\begin{array}{l}\text { Dysregulation of } \\
\text { signaling pathway }\end{array}$ & Molecular mechanism & Proposed function & References \\
\hline \multirow[t]{4}{*}{$\begin{array}{l}\text { Wnt/ß-catenin } \\
\text { signaling pathway }\end{array}$} & Competitive binding E-cadherin & $\begin{array}{l}\text { Release of } \beta \text {-catenin from the } \\
\text { E-cadherin/ } \beta \text {-catenin complex }\end{array}$ & {$[22]$} \\
\hline & Phosphorylation of LRP6 & Activation of Dvl & {$[34]$} \\
\hline & Phosphorylation of Akt & $\begin{array}{l}\text { Inactivation of GSK-3 } \beta \text { and activation } \\
\text { of downstream } \beta \text {-catenin }\end{array}$ & {$[37]$} \\
\hline & Direct binding GSK-3 $\beta$ & $\begin{array}{l}\text { Degradation of GSK-3 } \beta \text { and activation } \\
\text { of downstream } \beta \text {-catenin }\end{array}$ & {$[38]$} \\
\hline \multirow[t]{3}{*}{$\begin{array}{l}\text { P13K/Akt signaling } \\
\text { pathway }\end{array}$} & Phosphorylation of EGFR & $\begin{array}{l}\text { Activation of the P13K p85 subunit and } \\
\text { downstream Akt }\end{array}$ & {$[37,48]$} \\
\hline & Interaction with c-met & $\begin{array}{l}\text { Activation of P13K/Akt, the downstream } \\
\beta \text {-catenin and NF-KB }\end{array}$ & {$[21]$} \\
\hline & Interaction with P13K p85 & $\begin{array}{l}\text { Activation of the P13K p85 subunit and } \\
\text { downstream Akt }\end{array}$ & {$[20,50]$} \\
\hline \multirow[t]{2}{*}{ NF-kB signaling pathway } & Activation of MEK/ERK & $\begin{array}{l}\text { Phosphorylation of p65, induced the release } \\
\text { of IL-8 }\end{array}$ & {$[56,57]$} \\
\hline & $\begin{array}{l}\text { Autophosphorylation of TAK1 Synergy with } \\
\text { phosphorylation of MEKK3 }\end{array}$ & Recruitment and activation of IKK complex & {$[60]$} \\
\hline $\begin{array}{l}\text { Shh signaling } \\
\text { pathway }\end{array}$ & Activation of NF-KB & Overexpression of Shh & \\
\hline $\begin{array}{l}\text { JNK signaling } \\
\text { pathway }\end{array}$ & $\begin{array}{l}\text { Activation of TNF homolog Eiger or } \\
\text { overexpression of Rhol }\end{array}$ & $\begin{array}{l}\text { Upregulation of JNK signaling, induced } \\
\text { apoptosis and compensatory proliferation }\end{array}$ & {$[68,69]$} \\
\hline $\begin{array}{l}\text { JAK/STAT3 signaling } \\
\text { pathway }\end{array}$ & Induced IL-6, IL-10 & $\begin{array}{l}\text { Phosphorylation of STAT3, nuclear translocation } \\
\text { of STAT3 }\end{array}$ & [70-73] \\
\hline ERK/MAPK signaling pathway & Interaction with SHP2, Grb2 and Crk/Crk-L & $\begin{array}{l}\text { Activation of ERK/MAPK signaling, induced } \\
\text { cell scattering }\end{array}$ & {$[19,20,76]$} \\
\hline
\end{tabular}


the authors also used AID-transgenic mice to confirm that AID expression plays a critical role in the accumulation of p53 mutations [102]. These studies provide a mutation-dependent mechanism of $\mathrm{H}$. pylorimediated p53 inactivation.

Similar to p53, (i) Runt-related transcription factor 3 (RUNX3) is also a tumor suppressor, (ii) infection with CagA-positive H. pylori is associated with inactivation of RUNX3 in premalignant gastric lesions [103], (iii) CagA inhibits the expression of RUNX3 via the ERK/MAPK signaling pathway [104], (iv) CagA may increase the risk of RUNX3 promoter methylation [105], (v) CagA targets RUNX3 for ubiquitination and proteasome-mediated degradation [106]. In addition, the methylation of tumor suppressor genes is widespread in $H$. pylori-infected models. Cheng et al. used integrative genome-wide scans to identify genes that were concomitantly hypermethylated in mouse and human gastric cancer samples infected with $H$. pylori. They observed that the promoter hypermethylation of the Foxd3 tumor suppressor initiated by $H$. pylori infection affected the prognosis of gastric cancer patients [107]. H. pylori infection causes gastric mucosal inflammatory responses, resulting in upregulation of IL-1 $\beta$ and overproduction of nitric oxide (NO). IL-1 $\beta$ and NO play an important role in $H$. pyloriinduced methylation [108, 109]. Here, H. pylori-induced promoter methylation is observed not only in tumor suppressor genes but also in microRNAs (miRNAs). Silencing of these miRNAs promotes tumorigenesis through activation of their target oncogenes [110]. In general, CagA can decrease the levels of tumor suppressor proteins or inhibit their activity to inactivate of tumor suppressor pathways in a variety of ways.

\section{Conclusions}

Studies in diverse cell lines and animal models indicate that CagA is indispensable for H. pylori-induced tumorigenesis of gastric cancer. CagA acts as an initiator that activates multiple host cell signaling pathways via direct or indirect impacts on vital signaling proteins, thereby leading to signaling pathway-dependent oncogene upregulation (Table 1). In addition, CagA also acts as a repressor that inactivates tumor suppressor pathways. As a result, CagA promotes cell proliferation, transdifferentiation and reduces apoptosis, which is beneficial to tumorigenesis. Furthermore, CagA induces cell polarity and morphogenic changes, such as cell motility and scattering (known as the 'hummingbird phenotype') and the epithelial-mesenchymal transition, promoting development of gastric cancer. Accordingly, current guidelines strongly recommend treatments aimed at $H$. pylori eradication to prevent gastric cancer. However, few individuals infected by $H$. pylori may develop gastric cancer. Therefore, targeted CagA-positive H. pylori eradication may be more suitable for current personalized treatment strategies. A CagA detection kit has been used in clinical practice, but it is regrettable that there are currently no drugs that target CagA-positive $H$. pylori. On the other hand, the $H$. pylori-infected population is susceptible, and these individuals are easily reinfected with $H$. pylori after H. pylori eradication. H. pylori has coevolved alongside humans to promote persistent colonization of gastric mucosae. Focusing on the pathways implicated in H. pylori-induced tumorigenesis may lead to novel therapeutic strategies for gastric cancer prevention.

\section{Abbreviations \\ H. pylori: Helicobacter pylori; cag PAl: cag pathogenicity island: \\ VacA: Vacuolating cytotoxin A; CagA: Cytotoxin-associated gene A; T4SS: Type IV secretion system; PS: Phosphatidylserine; ERK: Extracellular signal-regulated kinase; MAPK: Mitogen-activated protein kinase; PI3K Akt: Phosphatidylinositol 3-kinase/Akt; NF-kB: Nuclear factor-kB; Fzd: Frizzled; LRP: Low-density lipoprotein receptor related protein; Dvl: Disheveled; GSK-

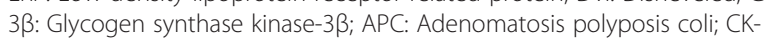 1: Casein kinase-1; WIF-1: Wnt inhibitory factor-1; sFRPs: Secreted Frizzled related proteins; DKKs: Dickkopf protein family; TCF/LEF: T cell factor/ lymphoid enhancer factor; PIP3: Phosphatidylinositol 3, 4, 5-triphosphate; PH: Plekstrin homology; mTOR: Mammalian target of rapamycin; EGFR: Epidermal growth factor receptor; TPMs: Tyrosine phosphorylation motifs; IKK: IKB kinase; TAK1: Transforming growth factor- $\beta$-activated kinase 1; FoxO: Forkhead transcription factors of class O; Hh: Hedgehog; Shh: Sonic hedgehog; JNK: c-Jun NH2-terminal kinase; STAT3: Signal transducers and activators of transcription 3; REG: Regenerating islet-derived; DCs: Dendritic cells; BMDCs: Bone marrow-derived dendritic cells; CAFs: Cancer-associated fibroblasts; FAK: Focal adhesion kinase; PKC: Protein kinase C; HDM2: Human double minute 2; ASPP2: Apoptosis-stimulating protein of p53; AID: Activation-induced cytidine deaminase; RUNX3: Runt-related transcription factor 3; NO: Nitric oxide; MiRNAs: microRNAs.}

\section{Competing interests}

The authors declare that they have no competing interests.

\section{Authors' contributions}

$\mathrm{XY}$ conceived of the review, and participated in its design and drafted the manuscript. BT contributed to Figure 1. B-SL contributed to Figure 2. RX contributed to Table. C-JH contributed to conception. GL helped to draft the manuscript. YQ contributed to references collection. HD gave final approval of the version to be published. S-MY participated in design and coordination and agreed to be accountable for all aspects of the work. All authors read and approved the final manuscript.

Received: 24 May 2015 Accepted: 3 July 2015

Published online: 11 July 2015

\section{References}

1. Malfertheiner P, Megraud F, O'Morain CA, Atherton J, Axon AT, Bazzoli F, et al. Management of Helicobacter pylori infection-the Maastricht IV/ Florence Consensus Report. Gut. 2012;61(5):646-64.

2. Franceschi F, Tortora A, Gasbarrini G, Gasbarrini A. Helicobacter pylori and extragastric diseases. Helicobacter. 2014;19 Suppl 1:52-8.

3. Hsu PI, Lai KH, Hsu PN, Lo GH, Yu HC, Chen WC, et al. Helicobacter pylori infection and the risk of gastric malignancy. Am J Gastroenterol. 2007;102(4):725-30.

4. Fukase K, Kato M, Kikuchi S, Inoue K, Uemura N, Okamoto S, et al. Effect of eradication of Helicobacter pylori on incidence of metachronous gastric carcinoma after endoscopic resection of early gastric cancer: an open-label, randomised controlled trial. Lancet. 2008;372(9636):392-7.

5. Delahay RM, Rugge M. Pathogenesis of Helicobacter pylori infection. Helicobacter. 2012;17 Suppl 1:9-15.

6. Polk DB, Peek Jr RM. Helicobacter pylori: gastric cancer and beyond. Nat Rev Cancer. 2010;10(6):403-14. 
7. Hayashi T, Senda M, Morohashi H, Higashi H, Horio M, Kashiba Y, et al. Tertiary structure-function analysis reveals the pathogenic signaling potentiation mechanism of Helicobacter pylori oncogenic effector CagA. Cell Host Microbe. 2012;12(1):20-33.

8. Ohnishi N, Yuasa H, Tanaka S, Sawa H, Miura M, Matsui A, et al. Transgenic expression of Helicobacter pylori CagA induces gastrointestinal and hematopoietic neoplasms in mouse. Proc Natl Acad Sci U S A 2008;105(3):1003-8.

9. Huang JQ, Zheng GF, Sumanac K, Irvine EJ, Hunt RH. Meta-analysis of the relationship between cagA seropositivity and gastric cancer. Gastroenterology. 2003;125(6):1636-44

10. Matos Jl, de Sousa HA, Marcos-Pinto R, Dinis-Ribeiro M. Helicobacter pylor CagA and VacA genotypes and gastric phenotype: a meta-analysis. Eur J Gastroenterol Hepatol. 2013;25(12):1431-41.

11. Kwok T, Zabler D, Urman S, Rohde M, Hartig R, Wessler S, et al. Helicobacter exploits integrin for type IV secretion and kinase activation. Nature. 2007:449(7164):862-6.

12. Jimenez-Soto LF, Kutter S, Sewald X, Ertl C, Weiss E, Kapp U, et al. Helicobacter pylori type IV secretion apparatus exploits beta1 integrin in a novel RGD-independent manner. PLoS Pathog. 2009;5(12):e1000684.

13. Kaplan-Turkoz B, Jimenez-Soto LF, Dian C, Ertl C, Remaut H, Louche A, et al. Structural insights into Helicobacter pylori oncoprotein CagA interaction with beta1 integrin. Proc Natl Acad Sci U S A. 2012;109(36):14640-5.

14. Murata-Kamiya N, Kikuchi K, Hayashi T, Higashi H, Hatakeyama M. Helicobacter pylori exploits host membrane phosphatidylserine for delivery, localization, and pathophysiological action of the CagA oncoprotein. Cell Host Microbe. 2010;7(5):399-411.

15. Stein M, Bagnoli F, Halenbeck R, Rappuoli R, Fantl WJ, Covacci A. C-Src/Lyn kinases activate Helicobacter pylori CagA through tyrosine phosphorylation of the EPIYA motifs. Mol Microbiol. 2002:43(4):971-80.

16. Tammer I, Brandt S, Hartig R, Konig W, Backert S. Activation of Abl by Helicobacter pylori: a novel kinase for CagA and crucial mediator of host cell scattering. Gastroenterology. 2007;132(4):1309-19.

17. Poppe M, Feller SM, Romer G, Wessler S. Phosphorylation of Helicobacter pylori CagA by c-Abl leads to cell motility. Oncogene. 2007;26(24):3462-72.

18. Backert S, Tegtmeyer N, Selbach M. The versatility of Helicobacter pylori CagA effector protein functions: The master key hypothesis. Helicobacter. 2010;15(3):163-76.

19. Higashi H, Tsutsumi R, Muto S, Sugiyama T, Azuma T, Asaka M, et al. SHP-2 tyrosine phosphatase as an intracellular target of Helicobacter pylori CagA protein. Science. 2002;295(5555):683-6.

20. Selbach M, Paul FE, Brandt S, Guye P, Daumke O, Backert S, et al. Host cell interactome of tyrosine-phosphorylated bacterial proteins. Cell Host Microbe. 2009;5(4):397-403.

21. Suzuki M, Mimuro H, Kiga K, Fukumatsu M, Ishijima N, Morikawa $H$, et al. Helicobacter pylori CagA phosphorylation-independent function in epithelial proliferation and inflammation. Cell Host Microbe. 2009;5(1):23-34.

22. Murata-Kamiya N, Kurashima $Y$, Teishikata $Y$, Yamahashi $Y$, Saito $Y$, Higashi $H$, et al. Helicobacter pylori CagA interacts with E-cadherin and deregulates the beta-catenin signal that promotes intestinal transdifferentiation in gastric epithelial cells. Oncogene. 2007;26(32):4617-26.

23. Zeaiter Z, Cohen D, Musch A, Bagnoli F, Covacci A, Stein M. Analysis of detergent-resistant membranes of Helicobacter pylori infected gastric adenocarcinoma cells reveals a role for MARK2/Par1b in CagA-mediated disruption of cellular polarity. Cell Microbiol. 2008;10(3):781-94.

24. Clevers H. Wnt/beta-catenin signaling in development and disease. Cell. 2006;127(3):469-80.

25. Klaus A, Birchmeier W. Wnt signalling and its impact on development and cancer. Nat Rev Cancer. 2008;8(5):387-98.

26. Baarsma HA, Konigshoff M, Gosens R. The WNT signaling pathway from ligand secretion to gene transcription: molecular mechanisms and pharmacological targets. Pharmacol Ther. 2013;138(1):66-83.

27. White BD, Chien AJ, Dawson DW. Dysregulation of Wnt/beta-catenin signaling in gastrointestinal cancers. Gastroenterology. 2012;142(2):219-32.

28. Oshima H, Matsunaga A, Fujimura T, Tsukamoto T, Taketo MM, Oshima M. Carcinogenesis in mouse stomach by simultaneous activation of the Wnt signaling and prostaglandin E2 pathway. Gastroenterology. 2006;131(4):1086-95.

29. Franco AT, Israel DA, Washington MK, Krishna U, Fox JG, Rogers AB, et al. Activation of beta-catenin by carcinogenic Helicobacter pylori. Proc Nat Acad Sci U S A. 2005;102(30):10646-51.
30. Kurashima Y, Murata-Kamiya N, Kikuchi K, Higashi H, Azuma T, Kondo S, et al. Deregulation of beta-catenin signal by Helicobacter pylori CagA requires the CagA-multimerization sequence. Int J Cancer. 2008;122(4):823-31.

31. Neal JT, Peterson TS, Kent ML, Guillemin K. H. pylori virulence factor CagA increases intestinal cell proliferation by Wnt pathway activation in a transgenic zebrafish model. Dis Model Mech. 2013;6(3):802-10.

32. Hsieh A, Kim HS, Lim SO, Yu DY, Jung G. Hepatitis B viral X protein interacts with tumor suppressor adenomatous polyposis coli to activate Wnt/beta-catenin signaling. Cancer Lett. 2011;300(2):162-72.

33. Fukutomi T, Zhou Y, Kawai S, Eguchi H, Wands JR, Li J. Hepatitis C virus core protein stimulates hepatocyte growth: correlation with upregulation of wnt-1 expression. Hepatology. 2005;41(5):1096-105.

34. Gnad T, Feoktistova M, Leverkus M, Lendeckel U, Naumann M. Helicobacter pylori-induced activation of beta-catenin involves low density lipoprotein receptor-related protein 6 and Dishevelled. Mol Cancer. 2010;9:31.

35. Sokolova O, Bozko PM, Naumann M. Helicobacter pylori suppresses glycogen synthase kinase 3beta to promote beta-catenin activity. J Biol Chem. 2008;283(43):29367-74

36. Nakayama M, Hisatsune J, Yamasaki E, Isomoto H, Kurazono H, Hatakeyama $M$, et al. Helicobacter pylori VacA-induced inhibition of GSK3 through the PI3KAAkt signaling pathway. J Biol Chem. 2009;284(3):1612-9.

37. Tabassam FH, Graham DY, Yamaoka Y. Helicobacter pylori activate epidermal growth factor receptor- and phosphatidylinositol 3-OH kinasedependent Akt and glycogen synthase kinase 3beta phosphorylation. Cell Microbiol. 2009;11(1):70-82.

38. Lee DG, Kim HS, Lee YS, Kim S, Cha SY, Ota I, et al. Helicobacter pylori CagA promotes Snail-mediated epithelial-mesenchymal transition by reducing GSK-3 activity. Nat Commun. 2014;5:4423.

39. Saijilafu, Hur EM, Liu CM, Jiao Z, Xu WL, Zhou FQ. PI3K-GSK3 signalling regulates mammalian axon regeneration by inducing the expression of Smad1. Nat Commun. 2013:4:2690.

40. Sha M, Ye J, Zhang LX, Luan ZY, Chen YB, Huang JX. Celastrol induces apoptosis of gastric cancer cells by miR-21 inhibiting PI3K/Akt-NF-kappaB signaling pathway. Pharmacology. 2014;93(1-2):39-46.

41. Xiao M, Tang Y, Wang YL, Yang L, Li X, Kuang J, et al. ART1 silencing enhances apoptosis of mouse CT26 cells via the PI3K/Akt/NF-kappaB pathway. Cell Physiol Biochem. 2013;32(6):1587-99.

42. Polivka Jr J, Janku F. Molecular targets for cancer therapy in the PI3K/AKT/ mTOR pathway. Pharmacol Ther. 2014;142(2):164-75.

43. Hales EC, Taub JW, Matherly LH. New insights into Notch1 regulation of the PI3K-AKT-mTOR1 signaling axis: targeted therapy of gamma-secretase inhibitor resistant T-cell acute lymphoblastic leukemia. Cell Signal. 2014;26(1):149-61.

44. Sokolova O, Vieth M, Gnad T, Bozko PM, Naumann M. Helicobacter pylori promotes eukaryotic protein translation by activating phosphatidylinositol 3 kinase/mTOR. Int J Biochem Cell Biol. 2014;55:157-63.

45. Ebi $H$, Costa $C$, Faber AC, Nishtala M, Kotani $H$, Juric D, et al. PI3K regulates MEK/ERK signaling in breast cancer via the Rac-GEF, P-Rex1. Proc Natl Acad Sci U S A. 2013;110(52):21124-9.

46. Almhanna K, Strosberg J, Malafa M. Targeting AKT protein kinase in gastric cancer. Anticancer Res. 2011;31(12):4387-92.

47. Cinti C, Vindigni C, Zamparelli A, La Sala D, Epistolato MC, Marrelli D, et al. Activated Akt as an indicator of prognosis in gastric cancer. Virchows Arch. 2008;453(5):449-55.

48. Bauer B, Pang E, Holland C, Kessler M, Bartfeld S, Meyer TF. The Helicobacter pylori virulence effector CagA abrogates human beta-defensin 3 expression via inactivation of EGFR signaling. Cell Host Microbe. 2012;11(6):576-86.

49. Churin Y, Al-Ghoul L, Kepp O, Meyer TF, Birchmeier W, Naumann M. Helicobacter pylori CagA protein targets the c-Met receptor and enhances the motogenic response. J Cell Biol. 2003;161(2):249-55.

50. Zhang XS, Tegtmeyer N, Traube L, Jindal S, Perez-Perez G, Sticht H, et al. A specific $A / T$ polymorphism in Western tyrosine phosphorylation B-motifs regulates Helicobacter pylori CagA epithelial cell interactions. PLoS Pathog. 2015;11(2):e1004621.

51. Hatakeyama M. Oncogenic mechanisms of the Helicobacter pylori CagA protein. Nat Rev Cancer. 2004;4(9):688-94.

52. Higashi H, Tsutsumi R, Fujita A, Yamazaki S, Asaka M, Azuma T, et al. Biological activity of the Helicobacter pylori virulence factor CagA is determined by variation in the tyrosine phosphorylation sites. Proc Natl Acad Sci U S A. 2002;99(22):14428-33.

53. Matsunari $O$, Shiota S, Suzuki R, Watada M, Kinjo N, Murakami K, et al. Association between Helicobacter pylori virulence factors and 
gastroduodenal diseases in Okinawa, Japan. J Clin Microbiol. 2012;50(3):876-83.

54. Hirata Y, Maeda S, Ohmae T, Shibata W, Yanai A, Ogura K, et al. Helicobacter pylori induces IkappaB kinase alpha nuclear translocation and chemokine production in gastric epithelial cells. Infect Immun. 2006;74(3):1452-61.

55. Sokolova O, Borgmann M, Rieke C, Schweitzer K, Rothkotter HJ, Naumann M. Helicobacter pylori induces type 4 secretion system-dependent, but CagA-independent activation of IkappaBs and NF-kappaB/RelA at early time points. Int J Med Microbiol. 2013;303(8):548-52.

56. Brandt S, Kwok T, Hartig R, Konig W, Backert S. NF-kappaB activation and potentiation of proinflammatory responses by the Helicobacter pylori CagA protein. Proc Natl Acad Sci U S A. 2005;102(26):9300-5.

57. Kim SY, Lee YC, Kim HK, Blaser MJ. Helicobacter pylori CagA transfection of gastric epithelial cells induces interleukin-8. Cell Microbiol. 2006;8(1):97-106

58. Kang DW, Hwang WC, Park MH, Ko GH, Ha WS, Kim KS, et al. Rebamipide abolishes Helicobacter pylori CagA-induced phospholipase D1 expression via inhibition of NFkappaB and suppresses invasion of gastric cancer cells. Oncogene. 2013;32(30):3531-42

59. Lamb A, Yang XD, Tsang YH, Li JD, Higashi H, Hatakeyama M, et al. Helicobacter pylori CagA activates NF-kappaB by targeting TAK1 for TRAF6mediated Lys 63 ubiquitination. EMBO Rep. 2009;10(11):1242-9.

60. Sokolova O, Maubach G, Naumann M. MEKK3 and TAK1 synergize to activate IKK complex in Helicobacter pylori infection. Biochim Biophys Acta. 2014;1843(4):715-24.

61. Tabassam FH, Graham DY, Yamaoka Y. Helicobacter pylori-associated regulation of forkhead transcription factors FoxO1/3a in human gastric cells. Helicobacter. 2012;17(3):193-202

62. Jiang J, Hui CC. Hedgehog signaling in development and cancer. Dev Cell. 2008;15(6):801-12

63. Kim JH, Choi YJ, Lee SH, Shin HS, Lee IO, Kim YJ, et al. Effect of Helicobacter pylori infection on the sonic hedgehog signaling pathway in gastric cancer cells. Oncol Rep. 2010;23(6):1523-8.

64. Schumacher MA, Feng R, Aihara E, Engevik AC, Montrose MH, Ottemann $\mathrm{KM}$, et al. Helicobacter pylori-induced Sonic Hedgehog Expression is Regulated by NFkappaB Pathway Activation: The Use of a Novel In vitro Model to Study Epithelial Response to Infection. Helicobacter. 2015;20(1):19-28.

65. Schumacher MA, Donnelly JM, Engevik AC, Xiao C, Yang L, Kenny S, et al. Gastric Sonic Hedgehog acts as a macrophage chemoattractant during the immune response to Helicobacter pylori. Gastroenterology. 2012;142(5):1150-9. e1156.

66. Gozdecka M, Lyons S, Kondo S, Taylor J, Li Y, Walczynski J, et al. JNK suppresses tumor formation via a gene-expression program mediated by ATF2. Cell Rep. 2014;9(4):1361-74.

67. Epstein Shochet G, Tartakover-Matalon S, Drucker L, Pasmanik-Chor M Pomeranz M, Fishman A, et al. Placenta-breast cancer cell interactions promote cancer cell epithelial mesenchymal transition via TGFbeta/JNK pathway. Clin Exp Metastasis. 2014;31(8):961-75.

68. Snider JL, Allison C, Bellaire BH, Ferrero RL, Cardelli JA. The beta1 integrin activates JNK independent of CagA, and JNK activation is required for Helicobacter pylori CagA + -induced motility of gastric cancer cells. J Biol Chem. 2008;283(20):13952-63.

69. Wandler AM, Guillemin K. Transgenic expression of the Helicobacter pylori virulence factor CagA promotes apoptosis or tumorigenesis through JNK activation in Drosophila. PLoS Pathog. 2012;8(10):e1002939.

70. Jackson CB, Judd LM, Menheniott TR, Kronborg I, Dow C, Yeomans ND, et al. Augmented gp130-mediated cytokine signalling accompanies human gastric cancer progression. J Pathol. 2007;213(2):140-51.

71. Bronte-Tinkew DM, Terebiznik M, Franco A, Ang M, Ahn D, Mimuro H, et al. Helicobacter pylori cytotoxin-associated gene A activates the signal transducer and activator of transcription 3 pathway in vitro and in vivo. Cancer Res. 2009;69(2):632-9

72. Lee KS, Kalantzis A, Jackson CB, O'Connor L, Murata-Kamiya N, Hatakeyama $M$, et al. Helicobacter pylori CagA triggers expression of the bactericidal lectin REG3gamma via gastric STAT3 activation. PLoS One. 2012;7(2):e30786.

73. Rizzuti D, Ang M, Sokollik C, Wu T, Abdullah M, Greenfield L, et al. Helicobacter pylori Inhibits Dendritic Cell Maturation via Interleukin-10Mediated Activation of the Signal Transducer and Activator of Transcription 3 Pathway. J Innate Immun. 2014;7:199.

74. Kao JY, Zhang M, Miller MJ, Mills JC, Wang B, Liu M, et al. Helicobacter pylori immune escape is mediated by dendritic cell-induced Treg skewing and Th17 suppression in mice. Gastroenterology. 2010;138(3):1046-54.
75. Oertli M, Sundquist M, Hitzler I, Engler DB, Arnold IC, Reuter S, et al. DCderived IL-18 drives Treg differentiation, murine Helicobacter pylori-specific immune tolerance, and asthma protection. J Clin Invest. 2012;122(3):1082-96.

76. Lee IO, Kim JH, Choi YJ, Pillinger MH, Kim SY, Blaser MJ, et al. Helicobacter pylori CagA phosphorylation status determines the gp130-activated SHP2/ ERK and JAK/STAT signal transduction pathways in gastric epithelial cells. J Biol Chem. 2010;285(21):16042-50.

77. Fukui H, Zhang X, Sun C, Hara K, Kikuchi S, Yamasaki T, et al. IL-22 produced by cancer-associated fibroblasts promotes gastric cancer cell invasion via STAT3 and ERK signaling. Br J Cancer. 2014;111(4):763-71.

78. Liao F, Hsu YC, Kuo SH, Yang YC, Chen JP, Hsu PN, et al. Genetic polymorphisms and tissue expression of interleukin-22 associated with risk and therapeutic response of gastric mucosa-associated lymphoid tissue lymphoma. Blood Cancer J. 2014;4:eXX.

79. Bard JD, Gelebart P, Anand M, Amin HM, Lai R. Aberrant expression of IL-22 receptor 1 and autocrine IL-22 stimulation contribute to tumorigenicity in ALK+ anaplastic large cell lymphoma. Leukemia. 2008;22(8):1595-603.

80. Gelebart P, Zak Z, Dien-Bard J, Anand M, Lai R. Interleukin 22 signaling promotes cell growth in mantle cell lymphoma. Transl Oncol. 2011;4(1):9-19.

81. Munari F, Fassan M, Capitani N, Codolo G, Vila-Caballer M, Pizzi M, et al. Cytokine BAFF released by Helicobacter pylori-infected macrophages triggers the Th17 response in human chronic gastritis. J Immunol. 2014;193(11):5584-94.

82. Trifari S, Kaplan CD, Tran EH, Crellin NK, Spits H. Identification of a human helper T cell population that has abundant production of interleukin 22 and is distinct from $T(H)-17, T(H) 1$ and $T(H) 2$ cells. Nat Immunol. 2009;10(8):864-71.

83. Tegtmeyer N, Wittelsberger R, Hartig R, Wessler S, Martinez-Quiles N, Backert $\mathrm{S}$. Serine phosphorylation of cortactin controls focal adhesion kinase activity and cell scattering induced by Helicobacter pylori. Cell Host Microbe. 2011;9(6):520-31.

84. Conradi J, Tegtmeyer N, Wozna M, Wissbrock M, Michalek C, Gagell C, et al. An RGD helper sequence in CagL of Helicobacter pylori assists in interactions with integrins and injection of CagA. Front Cell Infect Microbiol. 2012;2:70

85. Chen S, Duan G, Zhang R, Fan Q. Helicobacter pylori cytotoxin-associated gene A protein upregulates alpha-enolase expression via Src/MEK/ERK pathway: implication for progression of gastric cancer. Int J Oncol. 2014:45(2):764-70.

86. Xu X, Liu Z, Fang M, Yu H, Liang X, Li X, et al. Helicobacter pylori CagA induces ornithine decarboxylase upregulation via Src/MEK/ERK/c-Myc pathway: implication for progression of gastric diseases. Exp Biol Med. 2012;237(4):435-41.

87. Sokolova O, Vieth $\mathrm{M}$, Naumann M. Protein kinase C isozymes regulate matrix metalloproteinase-1 expression and cell invasion in Helicobacter pylori infection. Gut. 2013;62(3):358-67.

88. Gobbo Cesar AC, de Freitas Calmon M, Cury PM, Caetano A, Borim AA, Silva $A E$. Genetic alterations in benign lesions: chronic gastritis and gastric ulcer. World J Gastroenterol. 2006;12(4):625-9.

89. Ozturk Y, Ozer E, Lebe B, Bekem O, Buyukgebiz B. Immunohistochemical evaluation of p53 expression and proliferative activity in children with Helicobacter pylori associated gastritis. J Pediatr Gastroenterol Nutr. 2005;40(4):467-70.

90. Unger Z, Molnar B, Pronai L, Szaleczky E, Zagoni T, Tulassay Z. Mutant p53 expression and apoptotic activity of Helicobacter pylori positive and negative gastritis in correlation with the presence of intestinal metaplasia. Eur J Gastroenterol Hepatol. 2003;15(4):389-93.

91. Wei J, Nagy TA, Vilgelm A, Zaika E, Ogden SR, Romero-Gallo J, et al. Regulation of p53 tumor suppressor by Helicobacter pylori in gastric epithelial cells. Gastroenterology. 2010;139(4):1333-43.

92. Bhardwaj V, Noto JM, Wei J, Andl C, El-Rifai W, Peek RM, et al. Helicobacter pylori bacteria alter the p53 stress response via ERK-HDM2 pathway. Oncotarget. 2014;6:1531.

93. Wei J, Noto J, Zaika E, Romero-Gallo J, Correa P, El-Rifai W, et al. Pathogenic bacterium Helicobacter pylori alters the expression profile of p53 protein isoforms and p53 response to cellular stresses. Proc Natl Acad Sci U S A. 2012;109(38):E2543-50

94. Sherr CJ. Ink4-Arf locus in cancer and aging. Wiley Interdiscip Rev Dev Biol. 2012;1(5):731-41.

95. Wei J, Noto JM, Zaika E, Romero-Gallo J, Piazuelo MB, Schneider B, et al. Bacterial CagA protein induces degradation of p53 protein in a p14ARFdependent manner. Gut. 2014;64:1040.

96. Buti L, Spooner E, Van der Veen AG, Rappuoli R, Covacci A, Ploegh HL. Helicobacter pylori cytotoxin-associated gene A (CagA) subverts the 
apoptosis-stimulating protein of p53 (ASPP2) tumor suppressor pathway of the host. Proc Natl Acad Sci U S A. 2011;108(22):9238-43.

97. Nesic D, Buti L, Lu X, Stebbins CE. Structure of the Helicobacter pylori CagA oncoprotein bound to the human tumor suppressor ASPP2. Proc Natl Acad Sci U S A. 2014;111(4):1562-7.

98. Sato F, Meltzer SJ. CpG island hypermethylation in progression of esophageal and gastric cancer. Cancer. 2006;106(3):483-93.

99. Jenks PJ, Jeremy AH, Robinson PA, Walker MM, Crabtree JE. Long-term infection with Helicobacter felis and inactivation of the tumour suppressor gene p53 cumulatively enhance the gastric mutation frequency in Big Blue transgenic mice. J Pathol. 2003;201(4):596-602

100. Matsumoto Y, Marusawa H, Kinoshita K, Endo Y, Kou T, Morisawa T, et al. Helicobacter pylori infection triggers aberrant expression of activationinduced cytidine deaminase in gastric epithelium. Nat Med. 2007;13(4):470-6.

101. Nagata N, Akiyama J, Marusawa H, Shimbo T, Liu Y, Igari T, et al. Enhanced expression of activation-induced cytidine deaminase in human gastric mucosa infected by Helicobacter pylori and its decrease following eradication. J Gastroenterol. 2014;49(3):427-35.

102. Shimizu T, Marusawa H, Matsumoto Y, Inuzuka T, Ikeda A, Fujii Y, et al. Accumulation of somatic mutations in TP53 in gastric epithelium with Helicobacter pylori infection. Gastroenterology. 2014;147(2):407-17. e403.

103. Chung WC, Jung SH, Joo KR, Kim MJ, Youn GJ, Kim Y, et al. An inverse relationship between the expression of the gastric tumor suppressor RUNX3 and infection with Helicobacter pylori in gastric epithelial dysplasia. Gut Liver. 2013;7(6):688-95

104. Liu Z, Xu X, Chen L, Li W, Sun Y, Zeng J, et al. Helicobacter pylori CagA inhibits the expression of Runx3 via Src/MEK/ERK and p38 MAPK pathways in gastric epithelial cell. J Cell Biochem. 2012:113(3):1080-6.

105. Zhang YW, Eom SY, Yim DH, Song YJ, Yun HY, Park JS, et al. Evaluation of the relationship between dietary factors, CagA-positive Helicobacter pylori infection, and RUNX3 promoter hypermethylation in gastric cancer tissue. World J Gastroenterol. 2013;19(11):1778-87.

106. Tsang YH, Lamb A, Romero-Gallo J, Huang B, Ito K, Peek Jr RM, et al. Helicobacter pylori CagA targets gastric tumor suppressor RUNX3 for proteasome-mediated degradation. Oncogene. 2010;29(41):5643-50

107. Cheng AS, Li MS, Kang W, Cheng VY, Chou JL, Lau SS, et al. Helicobacter pylori causes epigenetic dysregulation of FOXD3 to promote gastric carcinogenesis. Gastroenterology. 2013;144(1):122-33. e129.

108. Huang FY, Chan AO, Lo RC, Rashid A, Wong DK, Cho CH, et al. Characterization of interleukin-1 beta in Helicobacter pylori-induced gastric inflammation and DNA methylation in interleukin-1 receptor type 1 knockout (IL-1R1(-/-)) mice. Eur J Cancer. 2013:49(12):2760-70.

109. Huang FY, Chan AO, Rashid A, Wong DK, Cho CH, Yuen MF. Helicobacter pylori induces promoter methylation of E-cadherin via interleukin-1 beta activation of nitric oxide production in gastric cancer cells. Cancer. 2012;118(20):4969-80.

110. Kiga K, Mimuro H, Suzuki M, Shinozaki-Ushiku A, Kobayashi T, Sanada T, et al. Epigenetic silencing of miR-210 increases the proliferation of gastric epithelium during chronic Helicobacter pylori infection. Nat Commun. 2014:5:4497.

\section{Submit your next manuscript to BioMed Central and take full advantage of:}

- Convenient online submission

- Thorough peer review

- No space constraints or color figure charges

- Immediate publication on acceptance

- Inclusion in PubMed, CAS, Scopus and Google Scholar

- Research which is freely available for redistribution 